\title{
A Inclusão Escolar de alunos com Deficiência no contexto das Escolas de Tempo Integral da Rede Pública
}

\author{
Jacqueline Gomes Herculano de Castro ${ }^{1}$; Edna Xenofonte Leite ${ }^{2}$; Maria Goretti Herculano Silva ${ }^{3}$
}

\begin{abstract}
Resumo: Esse estudo teve como objetivo desvelar o processo de inclusão de alunos com deficiência, no contexto das Escolas de Tempo Integral da rede pública brasileira. Essa temática tem motivado reflexões e debates relacionados às políticas públicas para a educação, bem como direcionado os olhares e discussões de alguns pesquisadores em seus trabalhos, os quais cita-se, Cavalieri (2002), Mauricio (2009), Glat, Pletsch e Fontes (2006) Mazotta (2005), Mantoan (1997) e Triñanes (2009) dentre outros, que proporcionaram considerações importantes concernentes aos temas. Optou-se pela pesquisa bibliográfica, buscando averiguar relações existentes entre a inclusão escolar e o modelo de Educação em Tempo Integral. Pôde-se constatar através dos relatos de muitos estudiosos dessa área, o descompasso relativo ao que é apresentado em lei e o que efetivamente tem acontecido na realidade escolar. A partir das leituras feitas acerca dos temas, foi possível perceber que não existe uma legislação específica que enquadre o estudante com deficiência nas ETIs. Acredita-se, no entanto, que medidas podem ser tomadas para que esse aluno, que já vive limitado, não seja tratado de forma injusta diante de um sistema educacional que deveria acolhê-lo. Portanto, considera-se que os órgãos cabíveis do Governo Federal, precisam com urgência efetuar mudanças para que realmente ocorra inclusão, e não uma exclusão disfarçada.
\end{abstract}

Palavras chave: Educação, Educação em Tempo Integral, Inclusão escolar.

\section{School Inclusion of Students with Disabilities in the context of Full-Time Public Schools Network}

\begin{abstract}
This study aims to unveil the process of inclusion of students with disabilities, in the context of the Schools of Integral of the Brazilian public network. This theme has motivated reflections and debates related to public policies for education, as well as directed the looks and discussions of some researchers in their works, which are cited, Cavalieri (2002), Mauricio (2009), Glat, Pletsch and Fontes (2006) Mazotta (2005), Mantoan (1997) and Triñanes (2009), among others, which provided important considerations concerning the themes. We opted for bibliographical research, seeking to ascertain the relationship between school inclusion and the model of Integral Education. It can be verified through the reports of many scholars in this area, the mismatch regarding what is presented in law and what has actually happened in the school reality. From the readings made about the themes, it was possible to perceive that there is no specific legislation that frames the student with deficiency in the ETIs. It is believed, however, what measures can be taken to ensure that this already limited student is not treated unfairly in the face of an educational system that should welcome him. Therefore, it is considered that the Federal Government's appropriate bodies urgently need to make changes so that inclusion does occur, not disguised exclusion.
\end{abstract}

Keywords: Education, Integral Education, School Inclusion.

\footnotetext{
1 Graduada em Educação Física pela Universidade de Fortaleza - UNIFOR, Especialista em Psicomotricidade pela Universidade Vale do Acaraú - UVA e mestranda em Educação pelo Mestrado Profissional em Educação - MPEDU da Universidade Regional do Cariri - URCA, jacqueline_herculano@hotmail.com

${ }^{2}$ Graduada em Pedagogia pela Universidade Regional do Cariri -URCA, Especialista em Educação Infantil pela Universidade Federal do Ceará- UFC e mestranda em Educação pelo Mestrado Acadêmico Intercampi em Educação -MAIE da Universidade Estadual do Ceará - UECE., ednaxenofonte@ yahoo.com.br

${ }^{3}$ Graduada em pedagogia pela Universidade Estadual do Ceará - UECE. Mestre em Educação e Doutora em Educação pela Universidade Federal do Ceará - UFC, goretti.herculano@ufca.edu.br
} 


\section{Introdução}

O presente estudo tem como objetivo desvelar o processo de inclusão de alunos com deficiência, no contexto das Escolas de Tempo Integral da rede pública brasileira. Assim, procurei através de uma revisão bibliográfica, compreender relações existentes entre a inclusão escolar e o modelo de Educação em Tempo Integral.

O interesse pelo estudo dessa temática foi despertado a partir da nossa prática pedagógica na sala de Atendimento Educacional Especializado (AEE) na Escola de Ensino Médio de Tempo Integral Wilson Gonçalves (EEMTIWG) em Crato-CE. A ideia se intensificou quando entramos no programa de Mestrado Profissional em Educação (MPEDU) da Universidade Regional do Cariri (URCA) e participamos da disciplina Educação Brasileira. Nesta, através da didática do professor, tivemos a oportunidade de sermos introduzidos em diversos cenários de períodos da Educação Brasileira, contemplando assim uma diversidade de políticas públicas inerentes a cada período histórico.

É importante para esse estudo entendermos o que é Educação especial e Educação Inclusiva. Glat e Fernandes (2005, p. 01) nos esclarecem acerca do que é a Educação Especial e de que maneira a inclusão entra nesse cenário:

\section{[...] a Educação Especial que por muito tempo configurou-se como um sistema paralelo de ensino, vem redimensionando o seu papel, antes restrito ao atendimento direto dos educandos com necessidades especiais, para atuar, prioritariamente como suporte à escola regular no recebimento deste alunado.}

Dessa forma, percebe-se que ao se tratar de Educação Especial, o termo é atribuído uma das modalidades de ensino, voltada para pessoas com limitação cognitiva, física, sensorial, mental ou múltipla. A Educação Inclusiva, por outro lado refere-se a iniciativas encaminhadas para a inserção de pessoas com deficiência nos contextos educacionais. Esse modelo se tem se adequado atualmente as Escolas de Tempo Integral.

A Educação em Tempo Integral tem motivado reflexões e debates relacionados às políticas públicas para a educação, bem como tem direcionado os olhares e discussões de alguns pesquisadores em seus trabalhos, os quais cita-se Gallo (2002), Cavalieri (2002), Gonçalves (2006) e Mauricio (2009), “que promoveram reflexões acerca das diversas proposições existentes e sobre a forma e a função da ampliação da jornada do aluno na escola" (SANTOS, 2013 p.11). 
Dentro desse grande universo, encontram-se estudantes com deficiência que estarão também inseridos no mesmo padrão de ensino, o que tem sido tema de muitos debates e pesquisas na área. Estudos como os de Glat, Pletsch e Fontes (2006), Mazotta (2005), Mantoan (1997) e Triñanes (2009) dentre outros, proporcionaram considerações importantes relacionadas à inserção do estudante com deficiência no ensino regular e nesse novo modelo de educação. Essa luta tem sido bastante retratada no meio educacional, fazendo parte da nossa mais remota história. Assim, é importante conhecer pontos destacados dessa trajetória.

\section{Cenário da Educação Inclusiva, um Tratado Histórico}

Pode-se dizer que no Brasil a trajetória da inclusão inicia-se ainda no período do império, ocasião em que ocorreram os primeiros atendimentos a crianças "excepcionais", nomenclatura usada na época. Em 1854, foi criado o Imperial Instituto dos Meninos Cegos, hoje o Instituto Benjamim Constant, (criado pelo Decreto Imperial № 1.428 de 12 de setembro de 1854), fundado por D. Pedro II, na capital do Império, cidade do Rio de Janeiro. Ainda no Rio, passados três anos, foi fundado o Imperial Instituto dos Surdos-mudos (Lei No 839 de 26 de setembro de 1857), hoje bastante conhecido como INES (Instituto Nacional de Educação de Surdos) (PLETSCH, 2009).

Essas Instituições agiam de forma isolada e o país carecia de legislação e políticas públicas que norteassem os gestores nessa área. A partir da Constituição de 1946, o ensino foi sancionado como direito universal e foi nesse período que as primeiras classes especiais foram criadas, separando assim os "normais" dos “anormais" (KASSAR, 1999; MAZZOTTA, 2005).

Foi com a primeira Lei de Diretrizes e Bases em 1961 que surge pela primeira vez uma preocupação direcionada ao atendimento do deficiente (art.88), porém no art. 89 ficara evidente que o Estado não assumiria por completo a aprendizagem desses alunos. Com isso houve um crescimento maior de instituições especializadas filantrópicas e assistenciais, surgindo então a Federação Nacional da Sociedade Pestalozi - FENASP - 1971, que ratificou o trabalho da Associação de Pais e Amigos dos Excepcionais - APAE -1954, passando em 1963 à denominação de Federação Nacional das Associações de Pais e Amigos dos Deficientes (PLETSCH, 2009). 
Assim, nas décadas de 60 e 70, muitas associações que promoviam a educação dos “excepcionais” surgiram e rapidamente se expandiram pelo País (PLETSCH, 2009). Também, na década de 70 , houve a instituição de classes especiais nas escolas públicas. No entanto, foi a partir da metade dos anos 80, com o processo de redemocratização, que essa tendência foi afirmada. "Neste movimento tomou vulto a luta pela ampliação do acesso e da qualidade da educação das pessoas com necessidades educacionais especiais." (GLAT, PLATSCH e FONTES, 2006, p.3)

Ainda nesse contexto, a SEESP Secretaria de Educação Especial é implementada em 1992. Com esse órgão governamental foram formuladas diretrizes institucionais relevantes que conduziriam o apoio educacional a ser ofertado aos estudantes com necessidades educacionais especiais (PLETSCH, 2009).

Dessa forma, em 1994, na cidade de Salamanca, na Espanha, acontece uma Conferência Mundial de Educação com a participação de 92 países, dentre os quais, o Brasil participava como um dos signatários. Esse evento foi promovido pela Organização das Nações Unidas para a Educação, Ciência e Cultura (UNESCO) e o Governo da Espanha. Como decorrência do evento, foi elaborada a Declaração de Salamanca, documento que versa sobre os princípios, políticas e práticas na área das necessidades educativas especiais. Parte do documento versa que:

$[\ldots]$ as crianças e jovens com necessidades educativas especiais devem ter acesso às escolas regulares, que a elas se devem adequar através duma pedagogia centrada na criança, capaz de ir ao encontro dessas necessidades, [...] (DECLARAÇÃO DE SALAMANCA, 1994, p. 7).

De acordo com o que foi decidido e aprovado pelos países que apoiaram o evento, as escolas regulares devem se ajustar às necessidades educacionais de cada aluno que as buscar. Diante de tal visão, esperou-se que esses alunos fossem devidamente amparados nas instituições escolares, respaldados com as preleções de lei do governo referentes à educação inclusiva. No entanto, o que é visto na prática é que a inclusão também ocorre não só devido a tantos discursos bem elaborados e convincentes, mas porque ela é economicamente viável para o Estado que tem uma grande preocupação nos menores custos atrelados ao não investimento na educação. Cabe aqui destacar a visão de Lombardi (2010, p. 228), quando faz uma estreita relação da educação com o capitalismo: 
A educação é um campo da atividade humana e os profissionais da educação não construíram esse campo segundo ideias próprias, mas em conformidade com condições materiais e objetivas, correspondendo às forças produtivas e relações de produção adequadas aos diferentes modos e organizações da produção, historicamente construídas pelos homens e particularmente consolidadas nas mais diferentes formações sociais.

Deste modo, Meszàros (2007), mostrando como é forte a atuação do capital sobre a educação, se refere à atuação dele como algo sem conserto "O impacto da lógica incorrigível do capital sobre a educação tem sido grande ao longo do sistema". Mostrando como se processa a educação nesse sistema econômico, o autor afirma que "apenas a mais vasta concepção de educação nos pode ajudar a insistir no objetivo de uma mudança verdadeiramente radical proporcionando alavancas que rompam a lógica mistificadora do capital” (p.118).

Nesse sentido, a limitação da educação faz parte da própria lógica do sistema de reprodução da sociedade capitalista. Ocorre, portanto, o ajuste de muitos interesses conflitantes à regra geral já estabelecida nessa sociedade, a qual nunca deveria ser mudada (Mészàros, 2004).

Com essa perspectiva, diversos movimentos na esfera do ensino, tem se levantado em nossos dias, indo desta forma contra essa possível passividade social. Nessa direção, pode-se dizer que ocorreram mudanças significativas em todos os níveis de ensino da Educação Básica à Superior, a partir da aprovação da LDB 9394/96.

Além de estabelecer que os sistemas de ensino devam garantir currículos, métodos, recursos e organização adequados ao atendimento das necessidades dos alunos, a LDB 9394/96 também define "oportunidades educacionais apropriadas, consideradas as características do alunado, seus interesses, condições de vida e de trabalho [...]” (BRASIL, 2010. p.12).

Percebe-se, desta forma, que a LDB de 1996 sinaliza para oportunizar o acesso de qualquer aluno à escola. Nesse sentido, a resolução $N^{\circ}$ 01/2002 do Conselho Nacional de Educação firma as Diretrizes Curriculares Nacionais para a formação de professores da educação básica, estabelecendo que as instituições de ensino superior devem ter em sua organização curricular a formação de professores "voltada para atenção à diversidade e que contemple conhecimentos sobre as especificidades dos alunos com necessidades educacionais especiais" (BRASIL, 2010. p.13). Seria, portanto necessária para o devido atendimento a estudantes com esse perfil, uma reorganização nos currículos existentes. 
Nesse aspecto, Ribeiro (2010), citando a reforma curricular na atualidade, elenca algumas tendências nas concepções de currículo. Uma delas, com base na Nova Sociologia da Educação - NSE inglesa, faz uma crítica aos currículos em vigor "por construírem identidades falsas e acabadas, consideradas como um objeto estático num contexto de mudança" (p. 136). Com relação à convivência social dos indivíduos, a NSE propõe então, uma educação que atenda à diversidade que encontramos no mundo pós-moderno, "a única possibilidade de nos relacionarmos uns com os outros seria o respeito às diferenças" (idem). É importante, portanto, acentuar no conceito de diferenças, não apenas o que se refere à pluralidade étnica, sexual e cultural, mas também perceber as diferenças no campo da limitação pessoal com as quais nos deparamos todos os dias, aprendendo a respeitá-las.

A atenção devida nas vidas de pessoas com deficiência foi o que motivou educadores a lutar por políticas educacionais que subsidiassem esse estudante com deficiência em seu processo de ensino. Elas têm registros marcantes na trajetória da educação em âmbito geral. Especificamente no campo da inclusão, em 2008, o Ministério da Educação estabelece a política nacional de educação com perspectiva na educação inclusiva, e a partir desse ano, a educação especial passa a compor o projeto pedagógico da escola de ensino regular, fomentando o atendimento aos alunos com deficiências (BRASIL, 2010).

Outro aspecto importante encontra-se nos Parâmetros Curriculares Nacionais, em seu volume introdutório, ao apresentarem que mesmo o aluno desenvolvendo atitudes diversas em função da sua natureza, "a escola tem como função potencializar o desenvolvimento de todas as capacidades, de modo a tornar o ensino mais humano" [...] (PCN, 1998, p.69). Nesse caso, o papel da escola é fundamental, para a construção de um novo olhar que tenha como meta incluir os alunos com necessidades educacionais especiais.

Nessa mesma perspectiva, no ano de 2015, a presidenta Dilma Roussef promulga a Lei Brasileira de Inclusão da pessoa com deficiência (PcD), especificamente no dia 6 de julho. Essa Lei chega como uma grande vitória dentro do contexto da educação inclusiva. Fazendo uma síntese da mesma, Reis, Mota e Jesus (2017, p. 09) afirmam que:

\footnotetext{
A lei 13.146/2015 estabelece atendimento prioritário e dá ênfase às políticas públicas nas áreas da educação, saúde, trabalho, infraestrutura urbana, esporte e cultura para a $\mathrm{PcD}$ e inova ao instituir o auxílio-inclusão, que será pago à $\mathrm{PcD}$ moderada ou grave que entrarem no mercado de trabalho, além de estabelecer pena de reclusão de um a três anos para quem discriminar a PcD e reservar $10 \%$ de vagas nos processos seletivos de curso de ensino superior, técnico e tecnológico para este público.
} 
Dessa forma, percebe-se a intenção da Lei no sentido de beneficiar à $\mathrm{PcD}$ em relação à todos os níveis da educação, além de abranger outras esferas sociais com esses direitos dantes inexistentes. Além disso, a legislação demonstra serem necessárias novas estruturas físicas e educacionais no sentido de fazer valer o que está escrito e aprovado por instâncias máximas do poder Estatal. Nessa perspectiva, "é preciso que todos que compõem essa estrutura educacional no Brasil estabeleçam diálogos permanentes", afim de que os desafios sejam vencidos e a finalidade máxima dessa lei seja alcançada (REIS, MOTA e JESUS, 2017, P. 11).

Desafios esses que perpassam todo o sistema educacional do país, especialmente para o modelo atual da educação Brasileira. Através da história é possível constatar os percalços e dificuldades de vários estudiosos e governantes na busca de um sistema educacional que pudesse desempenhar o crescimento ideal do aluno e da nação.

\section{Cenário da Educação em Tempo Integral no Brasil}

A ideia de uma escola que tenha um olhar diferenciado de ensino e que busque o crescimento do aluno em diferentes facetas, já existia aqui no Brasil na década de 1930 através de alguns educadores da época. Estes almejavam por metas educacionais que fugiam por completo da pedagogia vigente, a chamada Educação Tradicional. Anísio Teixeira era um desses "sonhadores", Cavalieri (2015, p. 531) fazendo uma síntese da compreensão desse educador brasileiro a respeito do processo educativo, afirma que:

[...] os preceitos da educação integral, observados na obra de Anísio Teixeira, defendem uma nova concepção pedagógica para as novas demandas que a conjuntura internacional anunciava para a sociedade brasileira em seu tempo. Assim, o modelo de ensino deveria primar pela ampliação do tempo e extensão do rol de matérias e experiências oferecidas no espaço escolar, para além das disciplinas propedêuticas.

Isso significa dizer que existiam saberes não ensinados ao aluno que faltavam no seu desenvolvimento escolar. $\mathrm{O}$ leque de ensinamentos necessários para um crescimento adequado ao estudante, não se restringia apenas nas matérias ofertadas pela escola desse tempo. Quanto maior o tempo do estudante na escola, melhor seria seu desempenho. Essa nova maneira de ensinar e aprender seriam dispostos paulatinamente ao educando, assim como ao educador. Referindo-se a essa nova metodologia, Silva (2015, p. 212) afirma: 
Todo esse processo seria gradativo, "progressivo". Fundando escolas experimentais de acordo com a preparação de professores e dedicando parte do dia escolar para os experimentos, aos alunos caberiam, de maneira orientada, escolherem as atividades a fim de vivenciar novas ambiências, operando o sentimento de responsabilidade e de autonomia.

Dessa forma o aluno seria protagonista da construção de seu conhecimento dentro de uma Instituição de ensino. No entanto, o modelo de escola que Anísio Teixeira queria não avançou na educação brasileira. Esse projeto foi travado em diversos aspectos, e quando o educador era questionado acerca das impossibilidades do mesmo, replicava:

É custoso e caro porque são custosos e caros os objetivos a que visa. Não se pode fazer educação barata - como não se pode fazer guerra barata. Se é a nossa defesa que estamos construindo, o seu preço nunca será demasiado caro, pois não há preço para a sobrevivência (Teixeira, 1994, p. 175).

Para Anísio Teixeira, o valor da educação era incalculável e qualquer esforço teria que ser empreendido nessa direção. A ideia das escolas parque, como eram nomeado os estabelecimentos de ensino projetados por ele, não progrediram. E na década de 1980, ainda sob a influência de Anísio, Darcy Ribeiro antropólogo e educador, juntamente com o então Governador do estado do Rio de Janeiro, Leonel Brizola, executam um projeto ousado de uma “ escola revolucionária em todos os sentidos, que atuaria como espaço privilegiado para a crítica das desigualdades e luta para a construção de uma sociedade mais justa"(MONTEIRO, 2009, p.41). Nessa linha de pensamento, Santos (2013, p. 13) afirma que na época:

Educadores cariocas, reunidos pela coordenação de Darcy, elaboraram para o governo de Brizola um projeto educacional que tinha como eixo central a implantação de escolas de tempo integral em todo o estado. Assim surgiram os Centros Integrados de Educação Pública (CIEPs), escolas de turno único voltadas principalmente para crianças oriundas das camadas mais pobres e carentes da população.

A estrutura física e educacional desse modelo de educação divergia em muitos pontos do sistema de ensino vigente e procurava alcançar em especial, crianças de classes populares. Foram vários os projetos sociais no campo do ensino, que surgiram depois desse padrão de escola. Estes programas se assemelhavam aos CIEPs e visavam ampliar a carga horária do estudante com atividades extracurriculares. Conforme aponta Santos (2013, p. 13):

Vários outros projetos se seguiram como os Centros Integrados de Educação Pública (CIEPs), no Rio de Janeiro, o Programa de Formação Integral da Criança (PROFIC), em São Paulo e o Centro de Educação Integral (CEI), em Curitiba. Atualmente, o 
governo federal desenvolve o Programa Segundo Tempo, uma parceria entre os Ministérios da Educação (MEC) e Esporte e associações do terceiro setor.

Dessa forma podemos perceber que a modalidade Educação em Tempo Integral, tem estado no sistema de ensino da federação desde tempos distantes. A LDB 9394/96 em seu artigo 34 reitera que "A jornada escolar no ensino fundamental incluirá pelo menos quatro horas de trabalho efetivo em sala de aula, sendo progressivamente ampliado o período de permanência na escola" (BRASIL, 1996). Assim, de forma gradativa os educandos iriam criando o hábito de manter-se na escola. Outro programa que veio confirmar a legislação que ampara a Educação em Tempo Integral foi o Mais Educação elaborado no ano de 2007. Sobre as metas desse trabalho, Cavalieri (2009, p. 55) declara que ele:

[...] visa formação em tempo integral de alunos da rede pública de ensino básico, através de um conjunto de ações educativas, do fortalecimento da formação cultural de crianças e jovens e da aproximação das escolas com as famílias e as comunidades.

Conforme a portaria de criação desse programa, ele não se limitava somente às Instituições públicas, a rede privada de ensino também poderia participar na promoção de "atividades educativas, culturais e desportivas" que estivessem inseridas "nos projetos políticos-pedagógicos das escolas." (Cavalieri, 2009 p. 55). Todas essas iniciativas fazem parte de um corpo de leis nacionais relacionadas à educação como atestam Sousa, Santos e Bernardo (2015, p. 150):

\begin{abstract}
A legislação brasileira aponta que sete horas diárias é o tempo mínimo de permanência do educando sob responsabilidade da escola para se considerar uma jornada de tempo integral. Tal indicação está expressa não somente na estratégia 6.1 do novo PNE, mas também na LDB, no PNE 2001-2010 e nos decretos $n^{\circ} 6.253 / 07$ e $n^{\circ} 7.083$.
\end{abstract}

É importante agora compreender as relações entre a escola integral e a educação inclusiva a partir dos desafios propostos para essa atuação em conexão e as possibilidades que se apresentam nesse campo.

\title{
Escola Integral e Educação Inclusiva: Desafios e Possibilidades
}

A partir de um maior aprofundamento nas leituras sobre a Escola de Tempo Integral (ETI) e a inclusão escolar de Pessoas com Deficiência (PcD) dentro desse novo modelo de educação, pudemos constatar que entre os pesquisadores que refletiram, discutiram e 
escreveram sobre esses temas, há aqueles que acreditam ser um avanço a presença de estudantes com esse perfil nas ETIs. Não obstante, existem também os que se contrapõem a esse pensamento, e não veem inclusão nesse modelo proposto pelo Estado.

Tomando essa proposta, é possível citar a meta 6 do atual Plano Nacional de Educação (PNE), que assegura a ampliação do educando com deficiência de maneira igualitária ao estudante "normal". Dessa forma o poder público vem:

\begin{abstract}
Garantir Educação em tempo integral para pessoas com deficiência, transtornos globais do desenvolvimento e altas habilidades ou superdotação, na faixa etária de 4 (quatro) a 17 (dezessete) anos, assegurando atendimento educacional especializado complementar e suplementar ofertado em salas de recursos multifuncionais da própria escola ou em instituições especializadas (BRASIL, 2014).
\end{abstract}

Nesse caso, as Instituições devem apresentar um atendimento com salas equipadas que tenham professores devidamente preparados e promovam estratégias educacionais individualizadas para cada perfil de estudante com deficiência. O que é lido na lei é belíssimo, no entanto o que é visto como prática nas escolas é uma estrutura que não tem funcionado. Trata-se de uma "inclusão excludente", como intitulou Kuenzer (2002, p. 14). A autora, referindo-se à expressão e na busca de explicá-la, declara:

\footnotetext{
As estratégias de inclusão nos diversos níveis e modalidades da educação escolar aos quais não correspondam os necessários padrões de qualidade que permitam a formação de identidades autônomas intelectual e eticamente, capazes de responder e superar as demandas do capitalismo.
}

Essas metodologias utilizadas pelos professores, não alcançam a demanda que o aluno necessita. O investimento nesse ramo da educação é insuficiente, pois o próprio sistema capitalista não tem nenhum interesse de financiar pessoas que não darão retorno capital à nação. Desse modo, o estudante com deficiência estaria vivendo uma igualdade ilusória , no entanto, a realidade é que essas situações são artifícios de uma falsa inclusão. Sendo assim, é possível perceber que a exclusão não deixa de existir, mesmo que seja de forma disfarçada (LEITE, 2017).

Isto posto, é necessário refletir a contramão do que foi exposto até agora nesse tópico e adentrar no pensamento dos estudiosos que defendem a presença de estudantes com deficiência nas Escolas de Tempo Integral. Segundo Carvalho (1997), o Ministério da Educação e Cultura, através do órgão responsável pela educação especial, tem procurado coordenar ações que envolvam as Secretarias dos Estados, bem como as dos municípios e do Distrito Federal, 
juntamente com ONGs que realizam o atendimento especializado. A autora ao tratar dessas relações, apresenta a distância ainda existente entre os protagonistas da educação especial e àqueles do ensino regular:

\begin{abstract}
Os interlocutores, apesar dos esforços de se envolver o ensino comum, costumam ser sempre os que trabalham na eduçação especial, reforçando-se, assim, a ideia de que ela é um subsistema que desenvolve ações em paralelo a um outro - o do ensino regular. E essa visão tradicional precisa ser modificada. O espírito da nova LDB permite isso; o que não se sabe é se os executores terão a vontade política necessária para tal mudança (CARVALHO, 1997, p. 76).
\end{abstract}

Isso significa dizer que apesar de todo amparo legal que a educação especial recebe para ser introduzida no ensino regular, é necessário políticos que tenham visão para tal transformação. Essa diretriz é bem clara na declaração de Salamanca quando esta afirma que estudantes com deficiência precisam ser acolhidos com "apoio adicional ao programa regular de estudos, em vez de seguir um programa diferente" (Declaração de Salamanca, 1994 p.29).

Para que ocorra esse diferencial, "o Conselho Nacional de Educação - CNE publica a Resolução CNE/CEHB, 04/2009” (BRASIL, 2015), a mesma viabiliza ao estudante com deficiência o Atendimento Educacional Especializado (AEE), que foi citado e detalhado em um tópico anterior. Este não abrange apenas a Educação Básica, alcançando também a educação superior do discente e acerca desse recurso, Carvalho (1997, p. 10) ainda considera o seguinte:

Parece fora de dúvida, portanto, que o MEC reconhece que, as necessidades educativas especiais de muitos se mantém, ao longo de sua vida acadêmica. Tal como as crianças, os jovens e adultos com necessidades especiais, principalmente quando são deficientes, têm direito, por cidadania, do apoio especializado, na própria educação superior. Não se trata, apenas, de remover barreiras arquitetônicas e atitudinais. Trata-se de dar, sem paternalismo, condições de acesso, ingresso e permanência, nos cursos de $3^{\circ}$ grau, a pessoas com necessidades especiais.

As dificuldades que essas pessoas atravessam são diversas em variadas intensidades. Contudo, por se tratar de leis federais, existe também todo um aparato de cobrança em cima dos professores das Salas de Recursos Multifuncionais. Essa exigência "se torna mais presente na ETI, que é posta para a inserção da classe social que está excluída da economia capitalista", assim é possível identificar o real intuito da política no campo educativo (TRIÑANES, 2009 p. 74).

Finalmente ao considerar as críticas feitas aos referidos temas e ao contexto dos pesquisadores que têm contribuído para a compreensão da importância da presença de estudantes com deficiência nas ETIs, percebe-se que é bem vasto o campo de discussões nas 
altas instâncias governamentais na área da educação, bem como diante das práticas pedagógicas diárias de cada docente.

\section{Considerações Finais}

Nessa jornada de estudos no campo da educação, especificamente tratando de Educação em Tempo Integral e a inclusão de estudantes com deficiência nesse novo modelo de ensino, pudemos constatar através dos relatos de muitos estudiosos dessa área, o descompasso relativo ao que é apresentado em lei e o que realmente tem acontecido na realidade escolar.

A partir das leituras feitas acerca dos temas, foi possível perceber que a inclusão de estudantes com deficiência nas ETIs, tem acontecido sem uma direção pré-determinada para a situação, ou seja, não existe uma legislação que enquadre esse educando em uma situação que favoreça o seu desempenho escolar. Este depende de diversas variantes como: professor capacitado para recebê-lo tanto na sala de ensino regular, quanto na Sala de Recursos Multifuncionais (SRM), estrutura física da escola, vestiários, armários individuais, sala de descanso, refeitório, tudo isso com os aparatos que a acessibilidade garante por lei.

Segundo as citações apresentadas nesse trabalho, é notório o propósito do sistema capitalista que se esconde por trás do governo e "impõe" uma produção em massa de mão de obra operária através desse novo modelo de educação. Essa premissa dificulta ainda mais a permanência do estudante com deficiência na escola, que tem de enfrentar uma jornada dupla de estudos, com salas superlotadas, professores mal pagos e despreparados e infraestrutura insuficiente.

Acredita-se, no entanto, que medidas podem ser tomadas para que esse aluno, que já vive limitado, não seja tratado de forma injusta diante de um sistema educacional que deveria acolhê-lo. Portanto considera-se que os órgãos cabíveis do governo federal, precisam com urgência efetuar mudanças para que realmente ocorra inclusão, e não uma exclusão disfarçada.

Essa pesquisa não tem a pretensão de apontar apenas as "falhas" da Educação em Tempo Integral, contudo é interessante expor que é preciso ressignificar conceitos e ações dessa modalidade de ensino tanto relacionado ao estudante com deficiência como o educando dito "normal". 


\section{Referências}

BRASIL, Ministério da Educação, (1997). Parâmetros Curriculares Nacionais para o Ensino Fundamental. Brasília, MEC/SEF.

BRASIL, Lei n ${ }^{\circ}$ 9.394/96, Diretrizes e Bases da Educação Nacional, aprovada na Câmara Federal em 17/12/96 e sancionada pelo Presidente da República em 20/12/96, Brasília, 1996. Disponível em: http://www.planalto.gov.br/ccivil_03/Leis/L9394.htm. Acesso em: 06/02/2018.

BRASIL, Orientações para implementação da Política de Educação Especial na Perspectiva da Educação Inclusiva. Conselho Nacional de Educação. Câmara de Educação Básica. Resolução n. 4, de 2 de outubro de 2009. Institui Diretrizes Operacionais para o Atendimento Educacional Especializado na Educação Básica, modalidade Educação Especial. Brasília, DF, 2009.

BRASIL.[Plano Nacional de Educação (PNE)]. Plano Nacional de Educação 2014-2024 [recurso eletrônico]: Lei ${ }^{\circ} 13.005$, de 26 de junho de 2014, que aprova o Plano Nacional de Educação (PNE) e dá outras providências - Brasília: Câmara dos Deputados, Edições Câmara, 2014.

CARVALHO, Rosita Edler. A nova $L D B$ e a Educação Especial. $3^{\text {a }}$ edição. Rio de Janeiro: WVA, 1997.

CAVALIERE, Ana Maria Vilella. Educação integral: uma nova identidade para a escola brasileira? Educação e Sociedade. Campinas, v. 23, n.81. 2002.

CAVALIERI, Ana Maria Vilella. Escolas de tempo integral versus alunos de tempo integral. Em Aberto, 2009.

CAVALIERI, Ana Maria Vilella: Currículo sem Fronteiras, v. 15, n. 2, p. 527-542, maio/ago. 2015.

DECLARAÇÃO DE SALAMANCA: Sobre Princípios, Políticas e Práticas na Área das Necessidades Educativas Especiais, 1994, Salamanca-Espanha.

GALLO, Silvio. A educação integral numa perspectiva anarquista. COELHO, Lígia Martha Coimbra da Costa e CAVALIERE, Ana Maria Vilella (Orgs.). Educação Brasileira em Tempo Integral. Petrópolis: Vozes, 2002.

GLAT, R; PLETSCH, M. D; FONTES, R. S. Uma Breve Reflexão sobre o Papel da Educação Especial Frente ao Processo de Inclusão de Pessoas com Necessidades Educacionais Especiais em Rede Regular de Ensino. Cadernos de Educação 6: Inclusão Social Desafios de uma Educação Cidadã. Rio de Janeiro: UNIGRANRIO Editora, 2006. 
GLAT, R; FERNANDES, E. M. Da educação segregada à educação inclusiva: uma breve reflexão sobre os paradigmas educacionais no contexto da educação especial brasileira Revista Inclusão, Universidade do estado do Rio de Janeiro. 2005.

GONÇALVES, Antônio Sérgio. Reflexões sobre educação integral e escola de tempo integral. Cadernos Cenpec, n.2, 2006.

KASSAR, M. de C. M. Deficiência Múltipla e Educação no Brasil: Discurso e Silencia na História de Sujeitos. São Paulo: Autores Associados, 1999.

KUENZER, A. no prelo. Exclusão includente e inclusão excludente: a nova forma de dualidade estrutural que objetiva as novas relações entre educação e trabalho. In: Anais do V Seminário Nacional de Estudos e Pesquisas - HISTEDBR, Campinas,UNICAMP, 2002.

LEITE, Michele de Mendonça. Educação Escolar da pessoa com deficiência e/ou necessidades especiais na escola de tempo integral. 2017. 197 f. Dissertação (Mestrado em Educação)Faculdade de Educação da Universidade Federal de Goiás, 2017.

LOMBARDI, J.C. Reflexões sobre educação e ensino na obra de Marx e Engels. Campinas, SP: Tese (livre docência) - Universidade Estadual de Campinas, Faculdade de Educação, [s.n.], 2010.

MANTOAN, M. T. E. Ser ou Estar - Eis a Questão - Explicando o Déficit Intelectual. Rio de Janeiro: WVA, 1997.

MAZZOTTA. M. J. S. Educação Especial no Brasil: História e Políticas Públicas. São Paulo: Editora Cortez, 2005.

MAURÍCIO, Lúcia Velloso. Escritos, representações e pressupostos da escola pública de horário integral. Revista Em Aberto. V.22, n.80. Brasília, 2009.

MÉSZÁROS, I. O poder da ideologia. São Paulo: Boitempo editorial, 2004

MÉSZÁROS, István. O desafio e o fardo do tempo presente. São Paulo: Boitempo, 2007. Cap. 8. 396p.

MONTEIRO, Ana Maria. Ciep - escola de formação de professores. Revista Em Aberto. V.22, n.80. Brasília. p. 35-49, abr. 2009.

PLETSCH, M. D. Repensando a inclusão escolar de pessoas com deficiência mental: Diretrizes Políticas, Currículo e Práticas Pedagógicas. Tese (Doutorado em Educação) - UERJ, Rio de Janeiro, 2009.

REIS, Anderson de Araújo; MOTA, Paloma Marcelino; JESUS. Lei Brasileira de Inclusão $N^{\circ}$ 13.146/2015: In: $10^{\circ}$ Encontro Internacional de Formação de professores. 2017, AracajúSergipe. Disponível em: $<$ http://www.anped.org.br/content/10o-encontro-internacional-deformacao-de-professores-enfope-e-o-11o-forum-permanente-de>. Acesso em: 10 fev. 2017. 
RIBEIRO, L. T. F. Questões Atuais sobre a Reforma Curricular. In: RIBEIRO, L. T. F; PATRÍCIO RIBEIRO, M. A. Temas Educacionais: Uma Coletânea de Artigos, Fortaleza: Coleção Diálogos Intempestivos, Edições UFC, 2010.

SANTOS, Fabrício Tineo. Educação de período integral e inclusão: Representações sociais do programa superescola. Pesquisa em Pós-graduação - Série Educação - nº 9, 2013.

SOUSA, Gustavo José Albino; SANTO,Nathalia Cortes do Espirito; BERNARDO, Elisangela da Silva. A sexta meta do PNE 2014-2024: Um diálogo possível em busca de uma Educação Integral e(m) Tempo Integral. Eccos; São Paulo (May-Aug 2015): 143-160.

SILVA, Bruno Adriano Rodrigues. Diferenças entre as Perspectivas de Educação Integral em Anísio Teixeira e no Programa Mais Educação. Revista HISTEDBR On-line, Campinas, nº 61, p. 202-218, mar2015.

SOUSA, Gustavo José Albino; SANTO,Nathalia Cortes do Espirito; BERNARDO, Elisangela da Silva. A sexta meta do PNE 2014-2024: Um diálogo possível em busca de uma Educação Integral e(m) Tempo Integral. Eccos; São Paulo (May-Aug 2015): 143-160.

TEIXEIRA. A. S. Educação não é privilégio. 5. ed. Rio de Janeiro: Editora UFRJ, 1994.

TRIÑANES, Maria Terêsa R. Nós sem nós: alunos com deficiência visual na escola de tempo integral. 2009. 149 fl. Dissertação (Mestrado em Educação). Programa de Pós-Graduação em Educação da Pontifícia Universidade Católica de Campinas. Campinas, 2009.

\section{Como citar este artigo (Formato ABNT):}

CASTRO, Jacqueline Gomes Herculano de Castro; LEITE, Edna Xenofonte; SILVA, Maria Goretti Herculano Silva. A Inclusão Escolar de alunos com Deficiência no contexto das Escolas de Tempo Integral da Rede Pública. Id on Line Rev.Mult. Psic., 2018, vol.12, n.41, p.991-1005. ISSN: 19811179 .

Recebido: $11 / 07 / 2018$.

Aceito: 26/07/2018 